\title{
High incidence of type III secretion system associated virulence factors (exoenzymes) in Pseudomonas aeruginosa isolated from Iranian burn patients
}

Ramin Khodayary ${ }^{1}$, Iraj Nikokar ${ }^{1,2,4^{*}}$, Mohammad Reza Mobayen ${ }^{3}$, Farhad Afrasiabi ${ }^{1}$, Afshin Araghian², Ali Elmi ${ }^{2}$ and Meisam Moradzadeh ${ }^{1}$

\begin{abstract}
Objective: The present study aimed to determine the prevalence of virulence factors and antimicrobial resistance profile of Pseudomonas aeruginosa strains isolated from Iranian burn patients.

Results: This cross-sectional study performed on 100 P. aeruginosa isolates which were recovered from burn wound specimens in 2014-2015. All presumptive isolates were identified by standard microbiologic tests. Antimicrobial susceptibility test was carried out by disk diffusion method. The presence of virulence genes was determined by PCR method. Antibiotic susceptibility results revealed that the isolates were mostly susceptible to amikacin (61\%), ceftazidime (60\%), and imipenem (55\%). Moreover, $59 \%$ of the isolates were multi-drug resistance (MDR). The most prevalent MDR pattern was aminoglycosides-penicillins-fluoroquinolones-carbapenems (15\%). The presence of exoT, exoY, exoS and exoU genes was detected in 100\%, 100\%, 59\%, and $41 \%$ of the tested isolates, respectively. Results points out the pattern of MDR and genetic diversity of type III secretion system among P. aeruginosa strains isolated from the burn population. Overall, the association of MDR and the presence of the specific virulence genes can be a predictive marker for the persistence of these isolates in the hospitals and subsequently a worse clinical condition for the affected patients.
\end{abstract}

Keywords: Pseudomonas aeruginosa, Virulence factors, Antimicrobial resistance, Burn patients, Type III secretion system

\section{Introduction}

Pseudomonas aeruginosa is an opportunistic Gram-negative pathogen that has been considered as a major cause of nosocomial infections, particularly in immunocompromised or patients with underlying diseases such as burn wounds $[1,2]$. P. aeruginosa causes a variety of acute infections in hospitalized patients associated with a high rate of morbidity and mortality [3]. Environmental contamination and direct spread from patients or healthcare

\footnotetext{
*Correspondence: nikokariraj@yahoo.com; nikokariraj@gums.ac.ir

${ }^{4}$ Laboratory of Microbiology and Immunology of Infectious Diseases, Paramedicine Faculty, Guilan University of Medical Sciences, P.O. Box: 44715-1361, Langeroud, IR, Iran

Full list of author information is available at the end of the article
}

workers are the most frequent reservoirs of $P$. aeruginosa in healthcare settings [4].

Pathogenicity of $P$. aeruginosa is attributed to the production of several extracellular and cell-associated virulence factors including those implicated in adherence, iron uptake, exoenzymes and exotoxins [5, 6]. Among the diversity of virulence determinants, the type III secretion system (T3SS) is considered as an important factor resulting in poor clinical outcome of $P$. aeruginosa infections in burn patients $[7,8]$. To date, this system is believed to be responsible for the injection of at least 4 effector proteins in $P$. aeruginosa, including Exoenzyme $\mathrm{S}$, Exoenzyme T, Exoenzyme $\mathrm{Y}$ and Exoenzyme U [8]. ExoS has been proposed as a major virulence factor required 
for colonization, invasion and bacterial dissemination in burns and chronic pulmonary infections. Also, this exoenzyme is a bifunctional effector protein, with GTPase activating protein (GAP) and ADP-ribosyltransferase (ADPRT) activities which can exert complex effects causing evading the pathogen from the host immune system and cells apoptosis. ExoT is a $53 \mathrm{kDa}$ protein with high homology and enzymatic activity with ExoS. It has been suggested that the GAP activity of ExoS and ExoT could prevent wound healing likely due to the disruption of the actin cytoskeleton, inhibition of bacterial internalization and phagocytosis, and host cells rounding. ExoU possesses a phospholipase A2-like activity resulting in extensive tissue destruction and modulation of the host inflammatory response. This protein contributes greatly in the pathogenesis of highly virulent strains and mostly is associated with the severity of $P$. aeruginosa infections. ExoY with natural adenylate cyclase activity causes an increase in intracellular signal messengers leading to disruption of the actin cytoskeleton and endothelial barriers. The outcome of these events is the dissemination of $P$. aeruginosa into the bloodstream and increased risk of septic shock $[7,8]$.

Due to the intrinsically and acquired resistance to the broad range of conventional antibiotics, treatment of the infections caused by $P$. aeruginosa has been limited [9]. Recently, the emergence of the multidrug resistance (MDR) P. aeruginosa strains producing extended spectrum $\beta$-lactamases (ESBLs) and metalo $\beta$-lactamases (MBLs) has become a global health concern $[10,11]$. It is not surprising that infections caused by MDR strains are associated with significant morbidity and mortality $[3,12]$. Therefore, investigation of $P$. aeruginosa virulence genes among MDR strains is waranted to prevent the spread of hyper virulent-resistant strains. Despite the significance of $P$. aeruginosa infection in burn patients, there is currently little local information on the distribution of the virulence factors to estimate the burden of toxin-producing isolates in Iran. The present study aimed to determine the prevalence of virulence factors and antimicrobial resistance profile of $P$. aeruginosa strains isolated from Iranian burn patients.

\section{Main text \\ Methods \\ Study design and bacterial isolates}

In this cross-sectional study, a total of 100 clinical isolates of $P$. aeruginosa were obtained from the burn wounds of the patients hospitalized in the Burn Center of Velayat burn injuries hospital (Guilan University of Medical Sciences, Rasht, Iran) during October 2014 to December 2015. This study was performed in accordance with the declaration of Helsinki and approved by the Ethics Committee of Guilan University of Medical Sciences. The exclusion criteria were taking any antibiotic treatment at least 1 week before sample collection. The burn wound samples were taken from the subjects using a sterile swab moistened with sterile physiological saline. Then, the swabs were transferred into tubes containing Stuart's transport medium (Merck, Germany) within $1 \mathrm{~h}$, and in the laboratory, were transferred onto the brain heart infusion (Merck, Germany) broth and incubated for overnight at $37^{\circ} \mathrm{C}$. All the presumptive isolates on MacConkey agar (Merck, Germany) were identified as $P$. aeruginosa using the standard microbiological methods including Gram staining, capacity for growth at $42{ }^{\circ} \mathrm{C}$, growth on Cetrimide agar (Merck, Germany), oxidase reaction, and IMViC tests. Confirmed P. aeruginosa isolates were stored in tryptic soy broth (TSB) (Merck, Germany) containing $30 \%$ glycerol at $-80{ }^{\circ} \mathrm{C}$ until further study.

\section{Antibiotic susceptibility test}

The antimicrobial susceptibility test was done by disk diffusion method on Mueller-Hinton agar (Merck, Germany) in accordance with the Clinical and Laboratory Standards Institute (CLSI) recommendations [13]. The following antibiotics were tested; Ceftazidime $(30 \mu \mathrm{g})$, Piperacillin $(100 \mu \mathrm{g})$, Gentamicin $(10 \mu \mathrm{g})$, Tobramycin $(10 \mu \mathrm{g})$, Amikacin $(30 \mu \mathrm{g})$, Ciprofloxacin $(5 \mu \mathrm{g})$, and Imipenem $(10 \mu \mathrm{g})$ (MAST Co., UK). Each agar plate with $20 \mathrm{ml}$ of Mueller-Hinton was incubated for 16-18 h at $37^{\circ} \mathrm{C}$. Control strains for susceptibility test were $P$. aeruginosa ATCC 27853. MDR was estimated as non-susceptible (including, resistant or intermediate) to at least 1 agent in $\geq 3$ antimicrobial categories according to the previously described definitions [14].

\section{Genomic DNA extraction and molecular assay}

Genomic DNA was extracted from the overnight TSB cultures of $P$. aeruginosa isolates using the boiling method as previously described [15]. The evaluation of exoT, exoY, exoS and exou genes were done by previously described primers (Table 1) [16]. PCR amplification was performed in $50 \mu \mathrm{l}$ reaction volume using Taq DNA polymerase. The reaction mixture consisted of $5 \mu \mathrm{l} 1 \times$ PCR buffer, $2 \mu \mathrm{l}$ of each primer, $1 \mu \mathrm{MgCl}_{2}, 0.8 \mu \mathrm{l}$ each of the dNTPs, $0.6 \mu \mathrm{l}$ Taq DNA polymerase, and a $2 \mu \mathrm{l}$ DNA each of isolate. All the reagents were obtained from the Cinnagene Co., Iran. Positive control strain for exoS, exoT, and exo $Y$ was $P$. aeruginosa PAO1 and for exo $U$ was PA103. The amplicons were resolved in 1.5\% agarose gel prepared in $1 \mathrm{X}$ TAE (Tris/Acetate/EDTA) buffer and visualized using an ultraviolet light after staining with safe stain loading dye (CinnaGen Co., Tehran, Iran). 
Table 1 List of used primers in the present study

\begin{tabular}{|c|c|c|c|c|}
\hline Primer & Oligonucleotide sequence ( $5^{\prime}$ to $\left.3^{\prime}\right)$ & Gene & Amplicon size (bp) & Reference \\
\hline exoT-F & AATCGCCGTCCAACTGCATGCG & exoT & 152 & [16] \\
\hline exoT-R & TGTTCGCCGAGGTACTGCTC & & & \\
\hline exoY-F & CGGATTCTATGGCAGGGAGG & exoY & 289 & \\
\hline exoY-R & GCCCTTGATGCACTCGACCA & & & \\
\hline exoU-F & CCGTTGTGGTGCCGTTGAAG & exol & 134 & \\
\hline exoU-R & CCAGATGTTCACCGACTCGC & & & \\
\hline exos-F & GCGAGGTCAGCAGAGTATCG & exos & 118 & \\
\hline exos-R & TTCGGCGTCACTGTGGATGC & & & \\
\hline
\end{tabular}

\section{Statistical analysis}

The analysis was performed by using SPSS $^{\mathrm{TM}}$ software, version 21.0 (IBM Corp., USA). The results are presented as descriptive statistics in terms of relative frequency. Values were expressed as the mean \pm standard deviation for continuous variables or percentages of the group for categorical variables. Data regarding categorized variables were analysed by Fisher's exact test and Chi square. A difference was considered statistically significant if the $P$ value was less than 0.05 .

\section{Results}

Of totally $100 P$. aeruginosa isolates included in our study, 65 were recovered from males and 35 from female's specimens with a mean age of $40.7 \pm 23.9$ years old, ranging from 1 to 87 year old. Results of the antibiotic susceptibility test revealed that tested $P$. aeruginosa isolates were mostly susceptible to amikacin (61\%), ceftazidime (60\%), and imipenem (55\%). In contrast, the lowest susceptibility rates were seen against tobramycin (32\%), ciprofloxacin (38\%), and piperacillin (39\%). The full results of antibiotic susceptibility profile for $P$. aeruginosa isolates were summarized in Table 2. Moreover, 59 (59\%) isolates out of the 100 tested were MDR. The most prevalent MDR pattern were aminoglycosides-penicillins-fluoroquinolones-carbapenems (15\%) followed by aminoglycosides-cephems-penicillins- fluoroquinolones-carbapenems (12\%), and aminoglycosides-cephems-penicillins-fluoroquinolones (9\%).

The presence of exoT, exo $Y$, exoS and exoU genes was detected in $100 \%, 100 \%, 59 \%$, and $41 \%$ of the tested isolates, respectively. Among the above mentioned genes, the presence of exoU gene had a statistically significant association with higher antibiotic resistance, and MDR rate (Table 3).

\section{Discussion}

Since, the high rate of morbidity and mortality of nosocomial infections in burn patients, the management of these infections is still a great challenge [17]. P. aeruginosa as a major cause of burn wound infections exhibits a remarkable ability to acquired resistance to antimicrobial agents [18]. MDR P. aeruginosa strains, as a growing public health concern, is moderately resulting from the limited therapeutic options [18].

In the present study, the frequency of MDR in Guilan province (Northern Iran) was estimated 59\%, which was lower than that of the studies conducted in capital of Iran in 2011-2013 (93.1\%-100\%) [19, 20], central parts of Iran in 2015 (95.8\%) [21], southwest of Iran in 2014 (76.4\%) [22], and Brazil in 2012 (71.4\%) [23], whereas it was higher than the studies performed in India in 2014 (33.9\%) [24], capital of Iran in 2008 (32.6\%) [25], and central parts of Iran in 2013 (26.7\%) [26]. These

Table 2 The antibiotic susceptibility testing results of 100 P. aeruginosa isolates

\begin{tabular}{lllcc}
\hline Class & Antibiotic & Susceptible (\%) & Intermediate-resistant (\%) & Resistant (\%) \\
\hline Penicillins & Piperacillin & 39 & 8 & 53 \\
Cephems & Ceftazidime & 60 & 7 & 33 \\
Carbapenems & Imipenem & 55 & 21 & 24 \\
Aminoglycosides & Gentamicin & 42 & 4 & 54 \\
& Amikacin & 61 & 13 & 26 \\
Fluoroquinolones & Tobramycin & 32 & 7 & 61 \\
\hline
\end{tabular}


Table 3 Distribution of virulence genes in relation with antibiotic resistance pattern

\begin{tabular}{|c|c|c|c|c|c|c|c|}
\hline Class & Antibiotic & $\begin{array}{l}\text { exoS positive } \\
(\mathrm{N}=59)\end{array}$ & $\begin{array}{l}\text { exoS negative } \\
(N=41)\end{array}$ & $P$ value & $\begin{array}{l}\text { exoU positive } \\
(N=41)\end{array}$ & $\begin{array}{l}\text { exoU negative } \\
(N=59)\end{array}$ & $P$ value \\
\hline Penicillins & Piperacillin & 29 & 10 & 0.013 & 10 & 29 & 0.013 \\
\hline Cephems & Ceftazidime & 31 & 29 & 0.068 & 29 & 31 & 0.068 \\
\hline Carbapenems & Imipenem & 38 & 17 & 0.023 & 17 & 38 & 0.023 \\
\hline \multirow[t]{3}{*}{ Aminoglycosides } & Gentamicin & 32 & 10 & 0.003 & 10 & 32 & 0.003 \\
\hline & Amikacin & 41 & 20 & 0.037 & 20 & 41 & 0.037 \\
\hline & Tobramycin & 25 & 7 & 0.008 & 7 & 25 & 0.008 \\
\hline Fluoroquinolones & Ciprofloxacin & 27 & 11 & 0.055 & 11 & 27 & 0.055 \\
\hline MDR positive & & $30(50.9)$ & $29(70.7)$ & 0.047 & $29(70.7)$ & $30(50.9)$ & 0.047 \\
\hline
\end{tabular}

Results presented as No. (\%)

differences in the prevalence of MDR strains might be attributed to the differences in geographical distribution, infection control policies, the nature of infections and sample size.

Carbapenems are important therapeutic agents for the treatment of the infections caused by MDR Gramnegative bacteria, particularly $P$. aeruginosa [27-29]. In our findings, the overall rate of carbapenems-non susceptible isolates was $45 \%$, while this rate in MDR isolates was $67.8 \%$. Such a high rate of carbapenemsresistant isolates in our region can be the result of indiscriminate prescription of these antibiotics as empirical therapies of infections caused by Gram-negative bacteria. However, our results were in consistent with the findings of the previous studies where the increased prevalence of carbapenem-non susceptible isolates in clinical settings was observed [21, 22, 30, 31].

The co-occurrence of exoT and exo $Y$ in our tested isolates was comparable with the previous findings in which the high presence of these genes in clinical isolates of $P$. aeruginosa was shown [32-34], while a minor impact of these exoenzymes on clinical outcome was suggested [34-36]. In the present study, in agreement with the previous reports, the exoS gene was the most prevalent exoenzyme in our tested isolates compared with exoU [23, 32, 33, 37, 38]. On the other hand, the presence of exoU gene compared to exoS gene was significantly associated with the higher antibiotic resistance. These findings were in agreement with the results of the studies conducted in Iran and other countries such as Korea, India, and Australia [39-41]. The precise mechanisms by which acquisition of the exoU results in higher antibiotic resistance are not known; however, it has been hypothesized that antibiotic-resistance may impose a lower fitness cost in the strains containing these specific genes, consequently leading to better adaptation to the antibiotic-rich clinical environment $[40,42]$. The dissemination of MDR $P$. aeruginosa strains with the ability to produce ExoU as a marker for highly virulent strains is a great concern due to restricted therapeutic options to treat these patients.

In summary, our data point out the pattern of MDR and the genetic diversity of type III secretion system associated exoenzymes. Also, the presence of exoU gene can be a predictive marker for the persistence of these $P$. aeruginosa strains isolated from the hospitals and consequently a worse clinical condition for the affected patients. However, in view of the limitations of the present study, further studies in larger series would be welcomed.

\section{Limitations}

The present study had some limitations; at first, the gene expression or enzymatic activity of the exoenzymes was not evaluated. Second, due to the lack of a molecular typing method, there was no mention of the coloniality of the isolated strains.

\section{Abbreviations}

T3SS: type III secretion system; Exo: exoenzyme S; MDR: multidrug resistance; MBLs: metalo $\beta$-lactamases; TSB: tryptic soy broth; CLSI: Clinical and Laboratory Standards Institute.

\section{Authors' contributions}

RK and IN: conceived the study. RK, MRM, FA, AA: participated in the design of the study and performed the statistical analysis. RK, MRM, AE, MM: interpreted the data. RK, IN, AE: obtained ethical clearance and permission for study. IN, AA, AE: Supervised data collectors. RK, FA, IN, AE: Drafting the article or revisiting it critically for important intellectual content. RK, MM, IN: were project leaders and primary investigators of the study. All authors read and approved the final manuscript.

\section{Author details \\ ${ }^{1}$ Department of Microbiology, Faculty of Medicine, Guilan University of Medi- cal Sciences, Rasht, Iran. ${ }^{2}$ Medical Biotechnology Research Center, School of Paramedicine, Guilan University of Medical Sciences, Rasht, Iran. ${ }^{3}$ Depart- ment of Surgery, Guilan University of Medical Science, Rasht, Iran. ${ }^{4}$ Laboratory of Microbiology and Immunology of Infectious Diseases, Paramedicine Faculty, Guilan University of Medical Sciences, P.O. Box: 44715-1361, Langeroud, IR, Iran.}

\section{Acknowledgements}

We thank all participants and personals at the studied hospital for their friendly cooperation. The authors wish to thank Dr. Kourosh Khanaki at Guilan 
University of Medical Sciences for his invaluable assistance in editing this manuscript.

\section{Competing interests}

The authors declare that they have no competing interests.

\section{Availability of data and materials}

The datasets used and/or analyzed during the current study are available from the corresponding author on reasonable request.

\section{Consent for publication}

Not applicable.

\section{Ethics approval and consent to participate}

This study was in accordance with the declaration of Helsinki and an ethical approval was sought from the institutional Ethics Committee of Guilan University of Medical Sciences (Approval No. 1930382811). However, because we only used leftovers from clinical specimens, the local ethics committee waived the need for informed consent.

\section{Funding support}

This study was supported by Guilan University of Medical Sciences. This funding source had no role in the design of this study and will not have any role during its execution, analyses, interpretation of the data, or decision to submit results.

\section{Publisher's Note}

Springer Nature remains neutral with regard to jurisdictional claims in published maps and institutional affiliations.

Received: 24 October 2018 Accepted: 11 January 2019

Published online: 15 January 2019

\section{References}

1. Mulcahy LR, Isabella VM, Lewis K. Pseudomonas aeruginosa biofilms in disease. Microb Ecol. 2014;68(1):1-12. https://doi.org/10.1007/s0024 8-013-0297-x

2. Ebrahimpour M, Nikokar I, Ghasemi Y, Sedigh Ebrahim-Saraie H, Araghian A, Farahbakhsh $M$, et al. Antibiotic resistance and frequency of class 1 integrons among Pseudomonas aeruginosa isolates obtained from wastewaters of a burn center in northern Iran. Ann Ig. 2018:30(2):112-9. https://doi.org/10.7416/ai.2018.2202.

3. Emami S, Nikokar I, Ghasemi Y, Ebrahimpour M, Sedigh Ebrahim-Saraie $\mathrm{H}$, Araghian $\mathrm{A}$, et al. Antibiotic resistance pattern and distribution of pslA gene among biofilm producing Pseudomonas aeruginosa isolated from waste water of a burn center. Jundishapur J Microbiol. 2015;8(11):e23669. https://doi.org/10.5812/jjm.23669.

4. Quick J, Cumley N, Wearn CM, Niebel M, Constantinidou C, Thomas CM, et al. Seeking the source of Pseudomonas aeruginosa infections in a recently opened hospital: an observational study using whole-genome sequencing. BMJ Open. 2014;4(11):e006278. https://doi.org/10.1136/ bmjopen-2014-006278.

5. Minandri F, Imperi F, Frangipani E, Bonchi C, Visaggio D, Facchini M et al. Role of iron uptake systems in Pseudomonas aeruginosa virulence and airway infection. Infect Immun. 2016;84(8):2324-35. https://doi. org/10.1128/iai.00098-16.

6. Hauser AR. Pseudomonas aeruginosa: so many virulence factors, so little time. Crit Care Med. 2011;39(9):2193-4. https://doi.org/10.1097/ CCM.0b013e318221742d.

7. Galle M, Carpentier I, Beyaert R. Structure and function of the Type III secretion system of Pseudomonas aeruginosa. Curr Protein Pept Sci. 2012;13(8):831-42.

8. Hauser AR. The type III secretion system of Pseudomonas aeruginosa: infection by injection. Nat Rev Microbiol. 2009;7(9):654-65. https://doi. org/10.1038/nrmicro2199.

9. Strateva T, Yordanov D. Pseudomonas aeruginosa - a phenomenon of bacterial resistance. J Med Microbiol. 2009;58(Pt 9):1133-48. https://doi. org/10.1099/jmm.0.009142-0.
10. Ramakrishnan K, Rajagopalan S, Nair S, Kenchappa P, Chandrakesan SD. Molecular characterization of metallo beta-lactamase producing multidrug resistant Pseudomonas aeruginosa from various clinical samples. Indian J Pathol Microbiol. 2014;57(4):579-82. https://doi. org/10.4103/0377-4929.142670.

11. Laudy AE, Rog P, Smolinska-Krol K, Cmiel M, Sloczynska A, Patzer J, et al. Prevalence of ESBL-producing Pseudomonas aeruginosa isolates in Warsaw, Poland, detected by various phenotypic and genotypic methods. PLoS ONE. 2017;12(6):e0180121. https://doi.org/10.1371/journ al.pone.0180121.

12. Tavakoly T, Jamali S, Mojtahedi A, KhanMirzaei M, Shenagari M. The prevalence of CMY-2, OXA-48 and KPC-2 genes in clinical isolates of Klebsiella spp. Cell Mol Biol (Noisy-le-grand). 2018;64(3):40-4. https://doi. org/10.14715/cmb/2018.64.3.7.

13. Wayne PA. Performance standards for antimicrobial susceptibility testing. In: 26th informational supplement. Wayne: Clinical and Laboratory Standards Institute (CLSI). 2016.

14. Magiorakos AP, Srinivasan A, Carey RB, Carmeli Y, Falagas ME, Giske CG, et al. Multidrug-resistant, extensively drug-resistant and pandrug-resistant bacteria: an international expert proposal for interim standard definitions for acquired resistance. Clin Microbiol Infect. 2012;18(3):268-81. https://doi.org/10.1111/j.1469-0691.2011.03570.x.

15. Nobari S, Shahcheraghi F, Rahmati Ghezelgeh F, Valizadeh B. Molecular characterization of carbapenem-resistant strains of Klebsiella pneumoniae isolated from Iranian patients: first identification of blaKPC gene in Iran. Microb Drug Resist. 2014;20(4):285-93. https://doi.org/10.1089/ mdr.2013.0074.

16. Lee JY, Peck KR, Ko KS. Selective advantages of two major clones of carbapenem-resistant Pseudomonas aeruginosa isolates (CC235 and CC641) from Korea: antimicrobial resistance, virulence and biofilm-forming activity. J Med Microbiol. 2013;62(Pt 7):1015-24. https://doi.org/10.1099/ jmm.0.055426-0.

17. Sydnor ER, Perl TM. Hospital epidemiology and infection control in acute-care settings. Clin Microbiol Rev. 2011;24(1):141-73. https://doi. org/10.1128/cmr.00027-10.

18. Dou Y, Huan J, Guo F, Zhou Z, Shi Y. Pseudomonas aeruginosa prevalence, antibiotic resistance and antimicrobial use in Chinese burn wards from 2007 to 2014. J Int Med Res. 2017;45(3):1124-37. https://doi. org/10.1177/0300060517703573.

19. Ghanbarzadeh Corehtash Z, Khorshidi A, Firoozeh F, Akbari H, Mahmoudi Aznaveh A. Biofilm formation and virulence factors among Pseudomonas aeruginosa isolated from burn patients. Jundishapur J Microbiol. 2015;8(10):e22345. https://doi.org/10.5812/jjm.22345.

20. Moazami-Goudarzi S, Eftekhar F. Assessment of carbapenem susceptibility and multidrug-resistance in Pseudomonas aeruginosa burn isolates in Tehran. Jundishapur J Microbiol. 2013;6(2):162-5. https://doi.org/10.5812/ jjm.5036.

21. Safaei HG, Moghim S, Isfahani BN, Fazeli H, Poursina F, Yadegari S, et al. Distribution of the strains of multidrug-resistant, extensively drugresistant, and pandrug-resistant Pseudomonas aeruginosa isolates from burn patients. Adv Biomed Res. 2017;6:74. https://doi.org/10.4103/abr. abr_239_16.

22. Khosravi AD, Shafie F, Abbasi Montazeri E, Rostami S. The frequency of genes encoding exotoxin A and exoenzyme $\mathrm{S}$ in Pseudomonas aeruginosa strains isolated from burn patients. Burns. 2016;42(5):1116-20. https ://doi.org/10.1016/j.burns.2016.02.012.

23. de Almeida Silva KCF, Calomino MA, Deutsch G, de Castilho SR, de Paula GR, Esper LMR, et al. Molecular characterization of multidrugresistant (MDR) Pseudomonas aeruginosa isolated in a burn center. Burns. 2017;43(1):137-43. https://doi.org/10.1016/j.burns.2016.07.002.

24. Biswal I, Arora BS, Kasana D, Neetushree. Incidence of multidrug resistant pseudomonas aeruginosa isolated from burn patients and environment of teaching institution. J Clin Diagn Res. 2014;8(5):26-9. https://doi. org/10.7860/jcdr/2014/7483.4383.

25. Salimi H, Yakhchali B, Owlia P, Lari AR. Molecular epidemiology and drug susceptibility of Pseudomonas aeruginosa strains isolated from burn patients. Lab Med. 2010;41(9):540-4. https://doi.org/10.1309/LMNIJE31ED C1WAMP.

26. Vaez H, Safaei HG, Faghri J. The emergence of multidrug-resistant clone ST664 Pseudomonas aeruginosa in a referral burn hospital, Isfahan. Iran. Burns Trauma. 2017;5:27. https://doi.org/10.1186/s41038-017-0092-x. 
27. Bubonja-Sonje M, Matovina M, Skrobonja I, Bedenic B, Abram M. Mechanisms of carbapenem resistance in multidrug-resistant clinical isolates of Pseudomonas aeruginosa from a Croatian Hospital. Microb Drug Resist. 2015;21(3):261-9. https://doi.org/10.1089/mdr.2014.0172.

28. Hosseinzadeh Z, Sedigh Ebrahim-Saraie H, Sarvari J, Mardaneh J, Dehghani B, Rokni-Hosseini SMH, et al. Emerge of blaNDM-1 and blaOXA48-like harboring carbapenem-resistant Klebsiella pneumoniae isolates from hospitalized patients in southwestern Iran. J Chin Med Assoc. 2017;1:1. https://doi.org/10.1016/j.jcma.2017.08.015.

29. Ghaffarian F, Hedayati M, Sedigh Ebrahim-Saraie H, Atrkar Roushan Z, Mojtahedi A. Molecular epidemiology of ESBL-producing Klebsiella pneumoniae isolates in intensive care units of a tertiary care hospital, North of Iran. Cell Mol Biol (Noisy-le-grand). 2018;64(7):75-9.

30. Neyestanaki DK, Mirsalehian A, Rezagholizadeh F, Jabalameli F, Taherikalani M, Emaneini M. Determination of extended spectrum beta-lactamases, metallo-beta-lactamases and AmpC-beta-lactamases among carbapenem resistant Pseudomonas aeruginosa isolated from burn patients. Burns. 2014;40(8):1556-61. https://doi.org/10.1016/j.burns.2014.02.010.

31. Sarhangi M, Motamedifar M, Sarvari J. Dissemination of Pseudomonas aeruginosa producing blaIMP1, blaVIM2, blaSIM1, blaSPM1 in Shiraz, Iran. Jundishapur J Microbiol. 2013;6(7):e6920. https://doi.org/10.5812/ jjm.6920.

32. Feltman $H$, Schulert $G$, Khan S, Jain M, Peterson L, Hauser AR. Prevalence of type III secretion genes in clinical and environmental isolates of Pseudomonas aeruginosa. Microbiology. 2001;147(Pt 10):2659-69. https://doi. org/10.1099/00221287-147-10-2659.

33. Georgescu M, Gheorghe I, Curutiu C, Lazar V, Bleotu C, Chifiriuc MC. Virulence and resistance features of Pseudomonas aeruginosa strains isolated from chronic leg ulcers. BMC Infect Dis. 2016;16(Suppl 1):92. https://doi. org/10.1186/s12879-016-1396-3.

34. Schulert GS, Feltman H, Rabin SD, Martin CG, Battle SE, Rello J, et al. Secretion of the toxin ExoU is a marker for highly virulent Pseudomonas aeruginosa isolates obtained from patients with hospital-acquired pneumonia. J Infect Dis. 2003;188(11):1695-706. https://doi.org/10.1086/379372.
35. Shaver CM, Hauser AR. Relative contributions of Pseudomonas aeruginosa ExoU, ExoS, and ExoT to virulence in the lung. Infect Immun. 2004;72(12):6969-77. https://doi.org/10.1128/iai.72.12.6969-6977.2004.

36. Lin HH, Huang SP, Teng HC, Ji DD, Chen YS, Chen YL. Presence of the exoU gene of Pseudomonas aeruginosa is correlated with cytotoxicity in MDCK cells but not with colonization in BALB/C mice. J Clin Microbiol. 2006:44(12):4596-7. https://doi.org/10.1128/jcm.01531-06.

37. Mitov I, Strateva T, Markova B. Prevalence of virulence genes among bulgarian nosocomial and cystic fibrosis isolates of Pseudomonas aeruginosa. Braz J Microbiol. 2010;41(3):588-95. https://doi.org/10.1590/s1517-83822 010000300008.

38. Fazeli N, Momtaz H. Virulence gene profiles of multidrug-resistant Pseudomonas aeruginosa isolated from Iranian hospital infections. Iran Red Crescent Med J. 2014;16(10):e15722. https://doi.org/10.5812/ircmj.15722.

39. Yousefi-Avarvand A, Khashei R, Sedigh Ebrahim-Saraie H, Emami A, Zomorodian K, Motamedifar M. The frequency of exotoxin A and exoenzymes $S$ and $U$ genes among clinical isolates of Pseudomonas aeruginosa in Shiraz, Iran. Int J Mol Cell Med. 2015;4(3):167-73.

40. Subedi D, Vijay AK, Kohli GS, Rice SA, Willcox M. Association between possession of ExoU and antibiotic resistance in Pseudomonas aeruginosa. PLoS ONE. 2018;13(9):e0204936. https://doi.org/10.1371/journ al.pone.0204936

41. Cho HH, Kwon KC, Kim S, Koo SH. Correlation between virulence genotype and fluoroquinolone resistance in carbapenem-resistant Pseudomonas aeruginosa. Ann Lab Med. 2014;34(4):286-92. https://doi. org/10.3343/alm.2014.34.4.286.

42. Agnello M, Finkel SE, Wong-Beringer A. Fitness cost of fluoroquinolone resistance in clinical isolates of Pseudomonas aeruginosa differs by type III secretion genotype. Front Microbiol. 2016;7:1591. https://doi. org/10.3389/fmicb.2016.01591.
Ready to submit your research? Choose BMC and benefit from:

- fast, convenient online submission

- thorough peer review by experienced researchers in your field

- rapid publication on acceptance

- support for research data, including large and complex data types

- gold Open Access which fosters wider collaboration and increased citations

- maximum visibility for your research: over 100M website views per year

At BMC, research is always in progress.

Learn more biomedcentral.com/submissions 